\section{Localization of CGRP and VEGF mRNAs in the mouse superior cervical ganglion during pre- and postnatal development}

\author{
Kazuyuki Mitsuoka, ${ }^{1}$ Yoko Miwa, ${ }^{2}$ \\ Takeshi Kikutani, ${ }^{3}$ Iwao Sato ${ }^{2}$ \\ ${ }^{1}$ Division of Orthodontics, Nippon \\ Dental University Hospital, Tokyo \\ ${ }^{2}$ Department of Anatomy, School of Life \\ Dentistry at Tokyo, Nippon Dental \\ University, Tokyo \\ ${ }^{3}$ Department of Clinical Oral \\ Rehabilitation, School of Life Dentistry \\ at Tokyo, Nippon Dental University, \\ Tokyo, Japan
}

\begin{abstract}
The neuropeptide calcitonin gene-related peptide (CGRP) mediates inflammation and head pain by influencing the functional vascular blood supply. CGRP is a well-characterized mediator of receptor-regulated neurotransmitter release. However, knowledge regarding the role of CGRP during the development of the superior cervical ganglion (SCG) is limited. In the present study, we observed the localization of CGRP and vascular endothelial growth factor (VEGFA) mRNAs during prenatal development at embryonic day 14.5 (E14.5), E17.5 and postnatal day 1 (P1) using in situ hybridization. The antisense probe for CGRP was detected by in situ hybridization at E14.5, $\mathrm{E} 17.5$, and $\mathrm{P} 1$, and the highest levels were detected at E17.5. In contrast, the antisense probe for VEGF-A was detected by in situ hybridization in gradually increasing intensity from E14.5 to P1. The differences in the expression of these two markers revealed specific characteristics related to CGRP concentration and release compared to those of VEGF-A during development. The correlation between CGRP and VEGF-A may influence functional stress and the vascular blood supply during prenatal and postnatal development.
\end{abstract}

\section{Introduction}

CGRP is a mediator of receptor-regulated neurotransmitter release and is related to vasculogenesis during differentiation and organ development. ${ }^{1}$ CGRP affects the expression of vascular endothelial growth factor (VEGFA). ${ }^{2}$ The neurochemical profile and peripheral and central targets differ in the mouse dor- sal root ganglia (DRG). ${ }^{3}$ The populations of axons and synaptic boutons in the sympathetic ganglia display CGRP and substance P-like immunoreactivity. CGRP first appears in the mouse on E16.5 and is located around blood vessels and near the cartilaginous bone matrix in the mouse limb. ${ }^{4}$ The axotomyinduced network of CGRP-immunoreactive nerve fibers may be related to the interaction between sympathetic and sensory neurons after peripheral nerves under physiological conditions and peptidergic nerve fiber localization during response to stress. ${ }^{5,6}$ Despite the similarities in the densities of CGRP axons in the superior cervical ganglion in normotensive and genetically hypertensive rats, ${ }^{7}$ the numbers of CGRP mRNA-positive inflammatory cells were increased in tissues in response to certain allergic reactions. ${ }^{8,9}$ Therefore, a functional alteration may also generate a population of CGRP-positive cells in the SCG during development. However, the CGRP expression patterns in ganglion cells of the SCG under various functional conditions during development are unknown. In contrast, functional alterations of peripheral nerves upregulate VEGF-A expression in Schwann cells and neurons. ${ }^{10}$ However, VEGF-A expression in the SCG during development has not been determined. During development, the population of neuronal nitric oxide synthase- and vasoactive intestinal peptide-positive reaction ganglion cells were increased in the cat stellate ganglion within the first 20 days of life compared to the SCG. ${ }^{11}$ Therefore, there is a need to assess the relationship between CGRP and angiogenesis markers in the SCG during development. VEGF-A acts as a neurotrophic factor and plays an important role during the regeneration of peripheral nerves between the superior cervical ganglia and dorsal root ganglia. ${ }^{12}$ The number of VEGF-immunoreactive neurons differs between the SCG and DRG during development. ${ }^{13}$ Moreover, no reports have examined the VEGF-A mRNA levels during SCG development. We observed the expression of these two factors in ganglion cells from mouse SCG at E14.5, E17.5 and P1 using in situ hybridization with anti-sense probes for CGRP and VEGF-A.

\section{Materials and Methods}

\section{Sample preparation}

All laboratory animals were procured from the Nippon Medical Science Animal Resource Laboratory and bred at the Animal Testing Center of the Dept. of Dentistry, Nippon Dental University. Male mice (CLER Japan, Inc.; Tokyo, Japan) were maintained on a solid pellet diet (MF; Oriental Yeast Inc., Tokyo, Japan). The
Correspondence: Dr. Iwao Sato, Department of Anatomy, School of Life Dentistry at Tokyo, Nippon Dental University, 1-9-20 Fujimi, Chiyoda-ku, Tokyo 102-8159, Japan. Tel. +81.3.32618531.

E-mail: iwaoa1@tokyo.ndu.ac.jp

Key words: Superior cervical ganglion; CGRP; development; ganglion cell.

Conflict of interest: The authors have no conflicts of interest to declare.

Received for publication: 27 August 2018. Accepted for publication: 14 November 2018.

This work is licensed under a Creative Commons Attribution-NonCommercial 4.0 International License (CC BY-NC 4.0).

(C) Copyright K. Mitsuoka et al., 2018

Licensee PAGEPress, Italy

European Journal of Histochemistry 2018; 62:2976 doi:10.4081/ejh.2018.2976

mice were used at E14.5, E17.5 and P1. The animals were sacrificed by pentobarbital overdose, and the right SCG was subsequently removed. Fresh samples isolated from the right SCG were prepared from four groups.

\section{In situ hybridization}

Tissues obtained during each stage $(\mathrm{n}=$ 4) were used for light microscopy studies. Paraffin-embedded intestine sections (6 $\mu \mathrm{m})$ from E14.5, E17.5 and P1 mice were obtained from Genostaff Co., Ltd., Tokyo, Japan. The tissue sections were deparaffinized with xylene and rehydrated through an ethanol series and PBS. The sections were fixed with $10 \% \mathrm{NBF}(10 \%$ formalin in $\mathrm{BS}$ ) for $15 \mathrm{~min}$ at room temperature (RT) and then washed with PBS. The sections were treated with $4 \mu \mathrm{g} / \mathrm{mL}$ proteinase $\mathrm{K}$ in PBS for $10 \mathrm{~min}$ at $37^{\circ} \mathrm{C}$, washed with PBS, and refixed with $10 \% \mathrm{NBF}$ for $15 \mathrm{~min}$ at RT to avoid tissue damage and prevent the sections from sliding off the glass slide. The sections were washed again with PBS and placed in $0.2 \mathrm{~N} \mathrm{HCl}$ for $10 \mathrm{~min}$ at RT. After washing with PBS, the sections were placed in 1x G-WASH (Genostaff Co., Ltd., Tokyo, Japan), which is equivalent to $1 \mathrm{x}$ SSC. In situ hybridization DNA fragments of CGRP (NM_001033954.3) and VEGF-A (NM_00950.4) were used in this study. The hybridization was performed using probes at concentrations of $300 \mathrm{ng} / \mathrm{mL}$ in G-Hybo (Genostaff Co., Ltd.) for $16 \mathrm{~h}$ at $60^{\circ} \mathrm{C}$. After hybridization, the sections were washed with $1 \mathrm{x}$ G-WASH for $10 \mathrm{~min}$ at $60^{\circ} \mathrm{C}$, followed by $50 \%$ formamide in $1 \mathrm{x}$ G-WASH for $10 \mathrm{~min}$ at $60^{\circ} \mathrm{C}$. Then, the sections were washed twice with $1 \mathrm{x}$ G-WASH for $10 \mathrm{~min}$ at $60^{\circ} \mathrm{C}$, twice with $0.1 \mathrm{x}$ G-WASH for 10 
min at $60^{\circ} \mathrm{C}$, and twice with TBST $(0.1 \%$ Tween 20 in TBS) at RT. After the treatment with 1x G-Block (Genostaff Co., Ltd.) for $15 \mathrm{~min}$ at RT, the sections were incubated with an AP-conjugated anti-DIG antibody (Roche Diagnostics, Indianapolis, IN, USA) diluted 1:2000 with 50x G-Block (Genostaff Co., Ltd.) in TBST for $1 \mathrm{~h}$ at RT. The sections were washed twice with TBST and then incubated with a buffer comprising $100 \mathrm{mM} \mathrm{NaCl}, 50 \mathrm{mM} \mathrm{MgCl} 2,0.1 \%$ Tween 20, and $100 \mathrm{mM}$ Tris- $\mathrm{HCl}, \mathrm{pH}$ 9.5. The color reactions were performed with an NBT/BCIP solution (Sigma-Aldrich Co. LLC, St. Louis, MO, USA) overnight, and the sections were subsequently washed with PBS. The sections were counterstained with Kernechtrot staining solution (Muto Pure Chemicals Co., Ltd., Tokyo, Japan) and mounted with G-Mount (Genostaff Co., Ltd.). Moreover, each serial section was stained to detect the different properties of ganglion cells in SCG by hematoxylin and eosin staining methods from E14.5 to P1.

\section{Analysis of images of positive reac- tions for CGRP and VEGF-A mRNAs in mouse SCG during development}

Each cell in the SCG was classified into three reaction levels based on the following responses of the ganglion cells in the spinal ganglion: weak, moderate, and strong reactions (Figure $1 \mathrm{a}-\mathrm{c}$ ). We acquired all digital images from each slide, which was scanned at an absolute magnification of $400 \times$ [resolution of $0.25 \mu \mathrm{m} /$ pixel (100,000 pix/in.)], and three slides obtained at E14.5, E17.5, and P1 were analyzed using the pixel density analysis method. ${ }^{14}$ The background illumination levels were also calibrated using a prescan procedure. Each stain was individually calibrated by analyzing single-stained sections and recording optical density (OD) vectors, such as the staining color. The average positive intensity (OD) was defined based on the percentage as weak (>1999 $\mathrm{OD}=1+$, density of Krajewska level ${ }^{15}$ ), moderate $(2000-69990 \mathrm{D}=2+)$, or strong $(7000 \mathrm{OD}<=3+$ ) positive staining. A localization algorithm using the deconvolution method was applied to separate the stains and classify each pixel according to the number of stains present. The algorithm also provides a green-color mark-up image for the visualization of the positive reactions (Figure $1 \mathrm{~d}-\mathrm{f}$ ). We also classified shrunken neurons ${ }^{15}$ in positive ganglion cells in our slides from E14.5 to P1.

\section{Statistical analysis}

The differences in the quantitative RealTime RT-PCR data among the experimental groups were assessed using a one-way analysis of variance (ANOVA), followed by
Bonferroni's post-hoc test, with one categorical independent variable and one continuous variable (the independent variable include several groups). The level of significance was set as $\mathrm{P}<0.05$. The results are reported as the means $\pm \mathrm{SD}$. All statistical analyses were performed using IBM SPSS
Statistics (Base, version 23) (New York, NY, USA).

\section{Ethics statement}

All procedures involving mice were reviewed and approved by the Nippon Medical Science Animal Resource

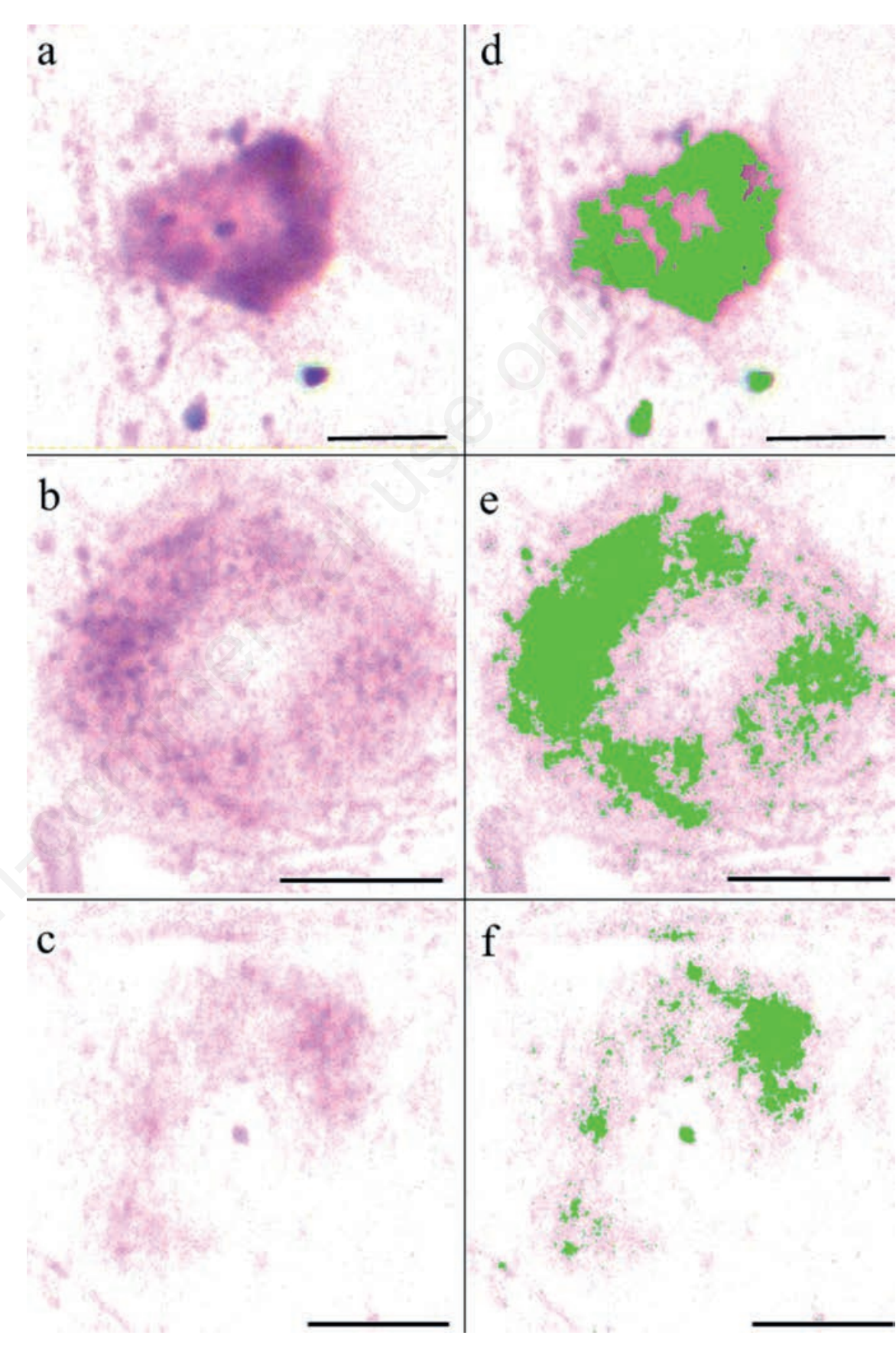

Figure 1. Three CGRP positive reaction cell types at P1. The expression of CGRP was assessed using in situ hybridization with an anti-sense probe. CGRP positive reactions in cells in the SCG at P1 were classified into the following three types; strong (panels a and d), moderate (panels $b$ and e) and weak (panels $c$ and $f$ ) reactions. Digital images of each cell were provided by the algorithm as green-color mark-up images for the visualization of the positive reactions (panels d-f). Scale bars: $10 \mu \mathrm{m}$. 
Laboratory Committee of the Nippon Dental University (No. 15-31).

\section{Results}

\section{Histochemical observations}

In the sagittal sections of the SCG, the neurons formed a cell mass that changed from an oval shape to an elongated form during the three stages of development of the SCG from E14.5 to P1 (Figure $2 \mathrm{a}-\mathrm{f}$ ). The SCG is mainly located beneath the middle ear in the mouse (Figure 2 a-c). A few myelin bundles and capillary vessels were also observed in the inferior region of the SCG (Figure $2 \mathrm{~d}-\mathrm{f}$ ). Numerous ganglion cells (Figure $2 \mathrm{f}-1$ ), satellite cells (Figure 2 $\mathrm{f}-3$ ) and a few shrunken neurons (Figure 2 $\mathrm{f}-2$ ) were observed in the SCG (Figure $2 \mathrm{~d}$ f).

\section{In situ hybridization in the mouse \\ SCG with positive reactions for CGRP and VEGF-A mRNAs during development}

In the E14.5 mice, a CGRP positive reaction was detected using an antisense probe, and the reaction was mainly found to be concentrated around the nuclei and cell membranes of SCG ganglion cells (Figure $3 b)$. In particular, the CGRP-positive reaction in the cells was found at the lateral zone of nuclei mainly located in the middle region of the SCG at E17.5 (Figure 3c). Moreover, the antisense probe used to detect the CGRP mRNA was only observed in a very few scattered CGRP-positive reaction ganglion cells and satellite cells in the P1 mice (Figure 3d). In the E14.5 mice, the intensity of the positive reaction for the VEGF-A mRNA was detected using an antisense probe, and this reaction was located in a few ganglion cells in the SCG (Figure 3 e-g). A few satellite cells surrounding the ganglion cells were positive for the antisense probe for VEGF-A mRNA in the E14.5 mice (Figure 3e). In the E17.5 SCG, numerous strong VEGF-A-positive reactions were detected in the ganglion cells (Figure 3f). At P1, a very large number of VEGF-A positive reactions in cell was found in the SCG (Figure 3g). The properties of the ganglion cells and positive reactions of CGRP and VEGF-A mRNAs in the cells in the mouse SCG were observed from E14.5 to P1 (Table 1).

We analyzed the ganglion cells, satellite cells, and shrunken neurons in the SCG from E14.5 to P1. At E17.5, the number of neurons was larger compared with that at $\mathrm{P} 1$ (statistically significant difference, $\mathrm{P}<0.01$ ). At P1 (statistically significant difference, $\mathrm{P}<0.01$ ) and E14.5 (statistically significant
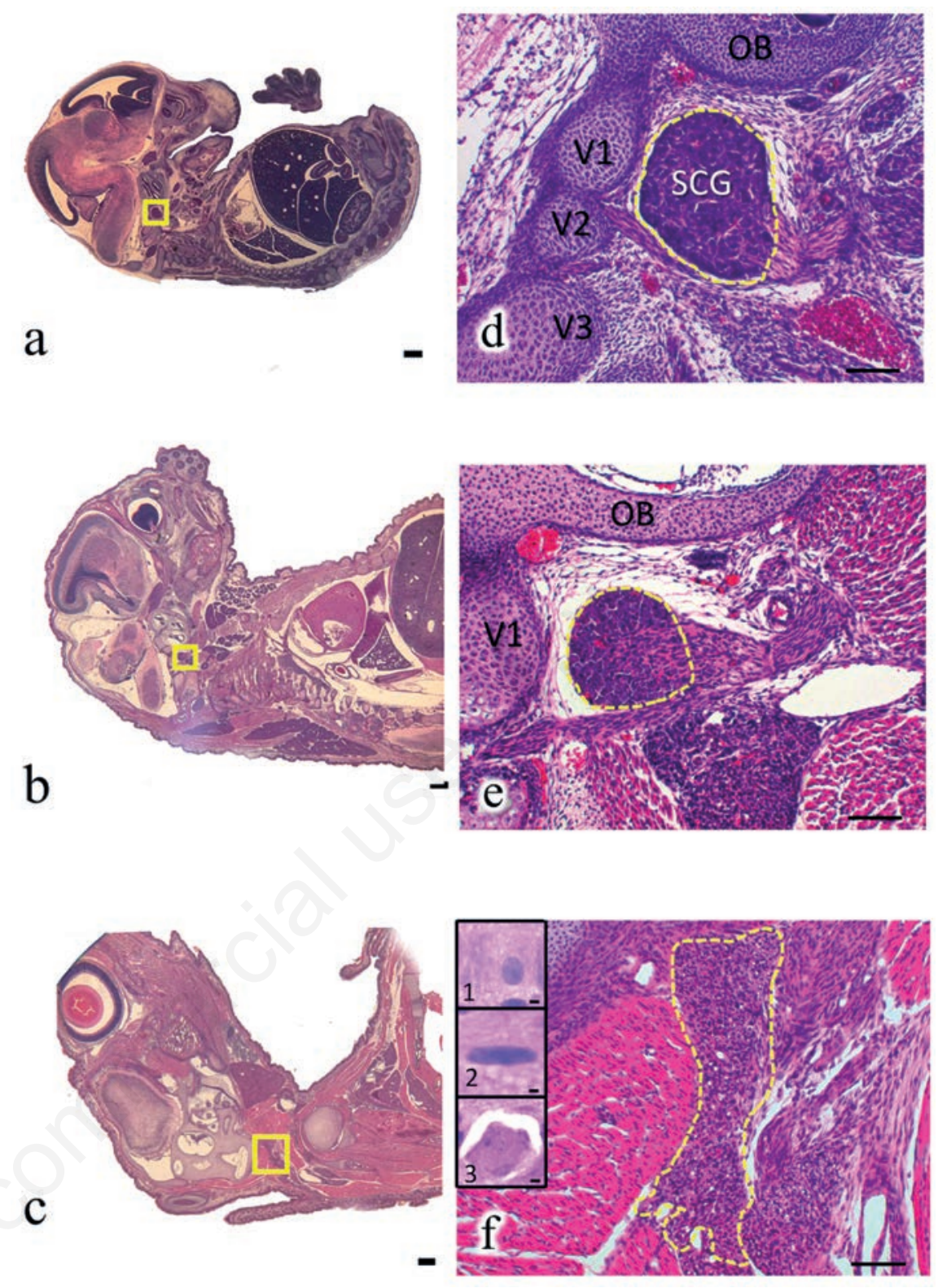

Figure 2. Hematoxylin \& Eosin staining of the SCG. In the sagittal sections of the whole body obtained during each stage, the neuron cell mass changed from an oval shape to an elongated form during the three stages of development of the SCG. a-c) Yellow squares are represented at higher magnification in panels d-f. a,d) SCG at E14.5. b,e) SCG at E17.5. c,f) SCG at P1. f) Ganglion cells (1), satellite cells (2), shrunken neurons with a vacant space (3). V1-3, cervical vertebrae; OB, occipital bone. Scale bars: a-c) $500 \mu \mathrm{m}$; df) $10 \mu \mathrm{m}$; f 1, 2, 3) $5 \mu \mathrm{m}$.

Table 1. The properties of ganglion cells using Hematoxylin \& Eosin staining in SCG from E14.5 to P1 (mean \pm SD).

\begin{tabular}{|c|c|c|c|c|}
\hline & Ganglion cell & & Satellite cell & Shrunken cell \\
\hline E14.5 & $27.1( \pm 10.8) \%$ & & $3.6( \pm 2.6) \%$ & $6.0( \pm 2.9) \%$ \\
\hline E17.5 & $31.0( \pm 13.3) \%$ & ** & $5.3( \pm 4.9) \%$ & $1.4( \pm 1.2) \%$ \\
\hline P1 & $5.5( \pm 2.2) \%$ & & $0.8( \pm 1.2) \%$ & $10.3( \pm 3.6) \%$ \\
\hline
\end{tabular}

${ }^{*} \mathrm{P}<0.05 ;{ }^{* *} \mathrm{P}<0.01 ;{ }^{* * *} \mathrm{P}<0.001$. 
difference, $\mathrm{P}<0.05$ ), the number of shrunken neurons was also larger than that at E17.5 (Table 1) (Figure $2 \mathrm{f} 2$ ). The number of CGRP mRNA-positive cells at E17.5 was larger than that at P1 (statistically significant difference, $\mathrm{P}<0.01$ ). At E14.5, the number of CGRP mRNA-positive cells was also larger than that at P1 (statistically significant difference, $\mathrm{P}<0.01$ ) (Table 2). At $\mathrm{P} 1$, the number of moderate reaction CGRP mRNA-positive cells was larger than that at E17.5 (statistically significant difference, $\mathrm{P}<0.05$ ) (Table 2). At E17.5, the number of VEGF-A mRNA-positive cells observed was larger than that at E14.5 $(\mathrm{P}<0.01)$ (Table 3).

\section{Discussion}

The proportion of early differentiated neuronal cells slightly decreased during the progression of spinal ganglia (SG) differentiation, while the number of neuronal subtypes expressing CGRP displaying differentiation increased at the later developmental stages. ${ }^{16}$ The number of ganglion cells may change from the postnatal to birth-period stages in the SCG during development. In general, no significant differences in the total number of myelinated axons were observed in the vagus nerve trunk of Wistar rats at 4, 24 and 30 months using montages of images of the entire cross-section of the nerve collected under a light microscope. ${ }^{17}$ During postnatal development, the number of neuronal fibers and the density of CGRPpositive fibers are significantly greater than those in the hairy skin of adult rats. ${ }^{18}$ During the studied period of intrauterine development, the nerve cells of the human trigeminal ganglion significantly differ in size. ${ }^{19}$ The alterations in the cell number during development indicate alterations in functional properties, such as the metabolic rate and other physiological traits, from the embryonic to adult stages. According to our results, the number of mouse ganglion cells at E17.5 was higher than that during the other examined stages. The ratio of CGRPpositive cells at E17.5 was also higher than that at other stages. During the development of the mouse SCG in late pregnancy, E17.5 is an important key stage determining the metabolic rate and other physiological traits. The plasma levels of the metabolic hormone fibroblast growth factor-21 (FGF21) were increased in mice from E18 to birth. ${ }^{20}$ In rat axotomized motoneurons, $\beta$-FGF regulates the expression of CGRP mRNAs as revealed by in situ hybridization methods. ${ }^{21}$ Therefore, metabolic hormones may control CGRP expression during late pregnancy. Neurons in the SCG undergo maturation and differentiation from E14.5 to P1 during development. According to Azuma reports, ${ }^{22}$ the expression of CGRP mRNA peaks at E17.5 in the mouse masseter muscle in response to the shift from embryonic MyHCs to adult MyHCs at E17.5. Moreover, the peak expression of CGRP mRNA was detected at E17.5 in the mouse tibia and at $\mathrm{P} 0$ in the mouse mandible. ${ }^{23}$ During bone formation, CGRP mRNA expression was increased during the embryonic stages beginning at E17.5. ${ }^{23}$ During late pregnancy, CGRP expression is regulated during the formation of mouse muscles and bones. Based on our results,
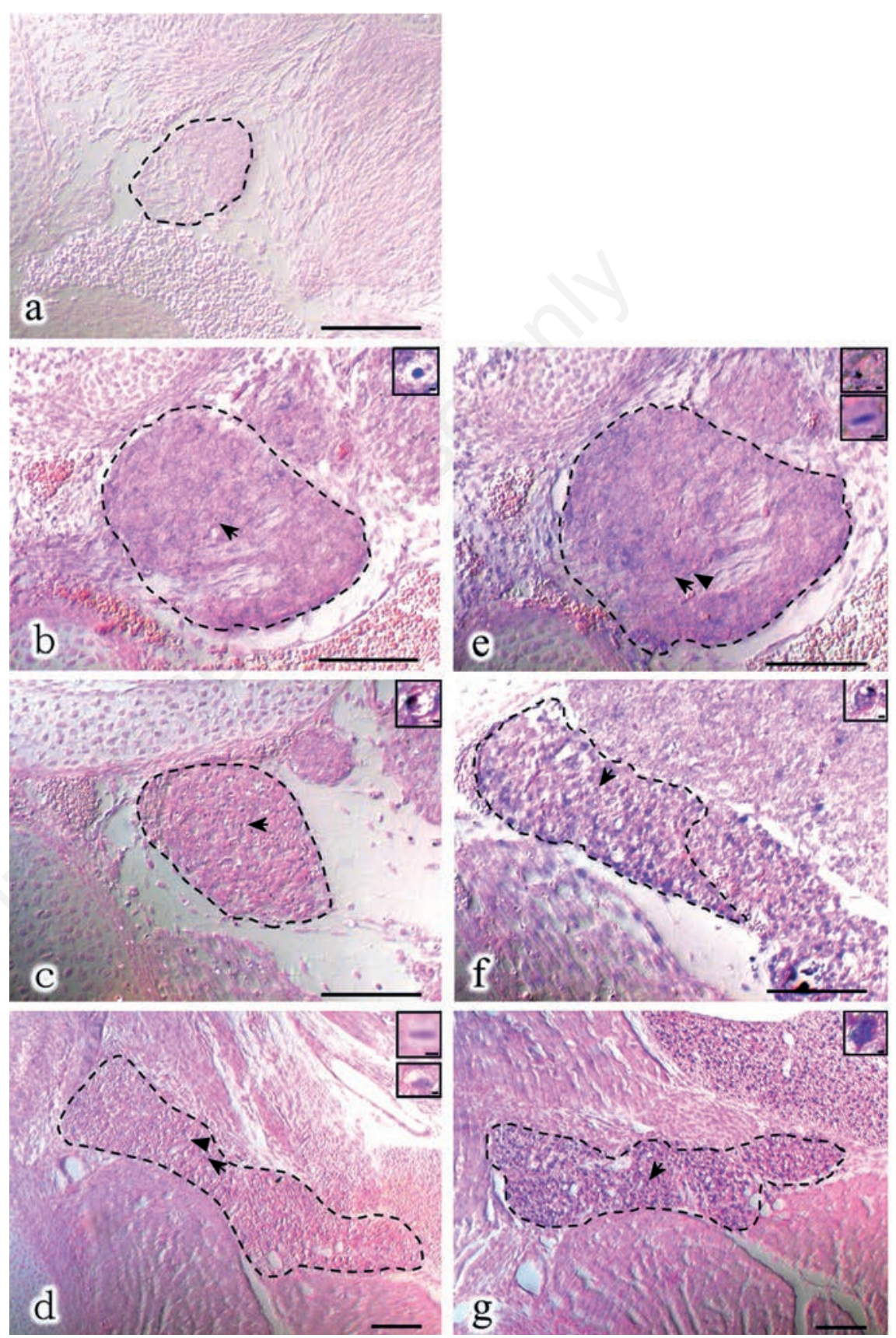

Figure 3. Expression of CGRP and VEGF-A was assessed using in situ hybridization with an anti-sense probe for CGRP (b,c,d) and VEGF-A (e,f,g) and a sense probe (a) in mouse heads from E14.5 to P1. Expression of CGRP was assessed using in situ hybridization with a sense probe (a) and an anti-sense probe (b) in mouse heads at E14.5. The CGRP reactions were detected at E14.5 (b), E17.5 (c) and P1 (d). Expression of VEGF-A was assessed using in situ hybridization with an anti-sense probe (e) in mouse heads at E14.5. VEGF-A reactions were detected at E14.5 (e), E17.5 (f) and P1 (g). Scale bars: $10 \mu \mathrm{m}$. 
the highest CGRP mRNA reaction was observed in the mouse SCG at E17.5. In the cat SCG, the expression of protein CGRP was appeared at immunohistochemical method at first after birth at 10 days. $^{24}$ However our results expression mRNA CGRP levels was obtained appeared at E14.5 and then peak of CGRP at E17.5 during period of embryonic stage ad at birth compared to that of protein levels cat SCG. The expression of CGRP have a various function to the formation of bone and muscle correlated vascular genesis as previously reported. 2,22,23 Therefore, CGRP may affect the formation of each organ with bone and muscle at postnatal stage. We need to examine the detail levels of the SCG CGRP in future. In general, the SCG communicates with branches of the superior laryngeal nerve, superior cervical cardiac branch, thyroid branch, pharyngeal branch and branches of the glossopharyngeal nerve. ${ }^{25,26}$ CGRP expression may affect communication with these regions. Moreover, we analyzed the distribution of VEGF mRNA in the mouse SCG from E14.5 to P1. During the postnatal (P0-12) and adult periods, the expression of VEGF and its receptor flk-1 was investigated in the SCG and DRG. ${ }^{13}$ In P0 mice, all neurons in the SCG and DRG expressed VEGF, and then, the number of VEGF-immunoreactive neurons in the DRG, but not the SCG, decreased postnatally and reached adult levels at P12, suggesting that temporal changes in VEGF and flk-1 expression occur in the peripheral ganglia. ${ }^{13}$ VEGF may regulate the expression of CGRP mRNA during mouse embryonic development. CGRP may affect the expression of VEGF. ${ }^{2}$ Functional alterations of peripheral nerves upregulate VEGF expression in Schwann cells and neurons. ${ }^{10}$ As shown in our results, CGRP mRNA was expressed at high levels at E17.5, and the levels of VEGF mRNA continued to increase during development. In the mouse SCG, the expression of these two markers changes with the developmental stage. The production and concentration of CGRP continue until E17.5, and CGRP is subsequently released and transported to nerve-supplied areas in response to stress before and after birth and decreases at P1. In contrast, VEGF expression is increased as a result of CGRP expression (Figure 4). A previous study examined neurobehavioral impairments associated with prenatal stress. ${ }^{27}$ Prenatal stress impairs motor development, decreases attention, and delays cognitive development in offspring during the first year of life..$^{28}$ In general, CGRP acts as a neuromodulator under neuropathic, inflammatory and non-headache pain conditions. ${ }^{29}$ CGRP accumulates in the nerve fibers of various tissues during develop- ment. ${ }^{4,22,30-36}$ CGRP continues to accumulate in response to prenatal stress. Therefore, CGRP gradually accumulates in the SCG from E14.5 to P1 with possible subsequent

in the each organ through nerve fibers development.

Table 2. The ratio of CGRP positive cells in the SCG from E14.5 to P1 (mean \pm SD) cell count CGRP.

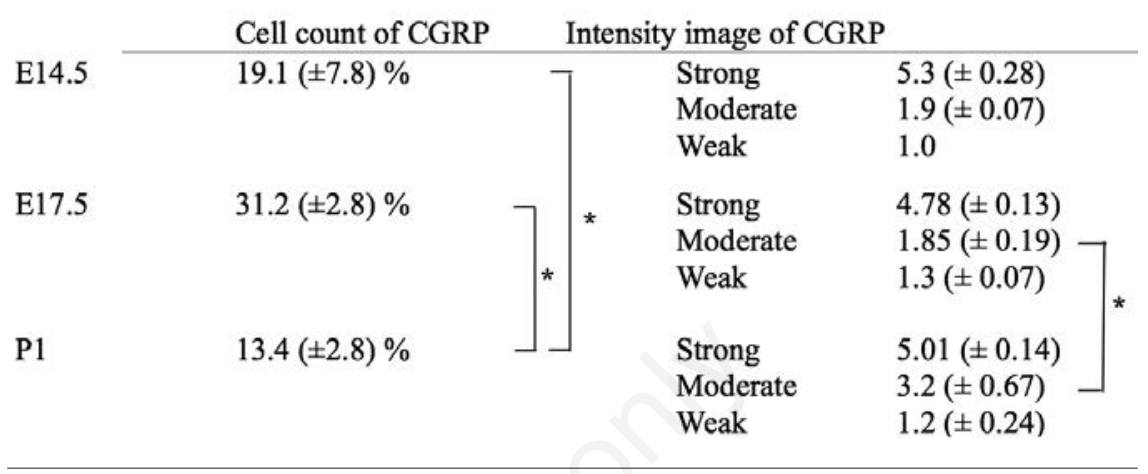

${ }^{*} \mathrm{P}<0.05 ;{ }^{* *} \mathrm{P}<0.01 ; * * * \mathrm{P}<0.001$.

Table 3. The ratio of VEGF-A positive cell (mean \pm SD) cell count of VEGF-A.

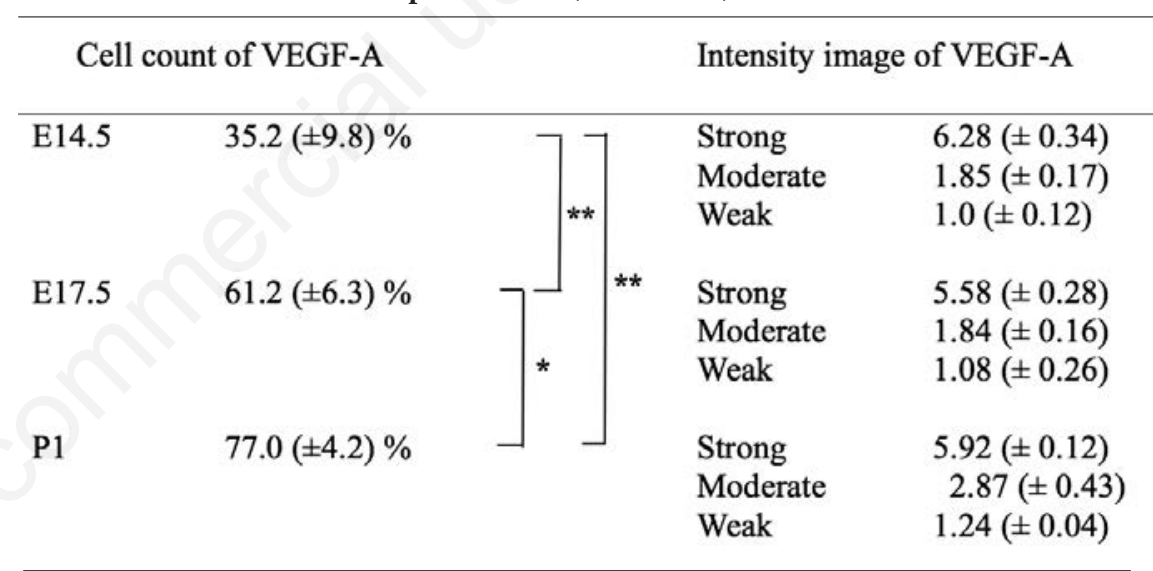

${ }^{*} \mathrm{P}<0.05 ;{ }^{*} \mathrm{P}<0.01 ;{ }^{* *} \mathrm{P}<0.001$

E14.5

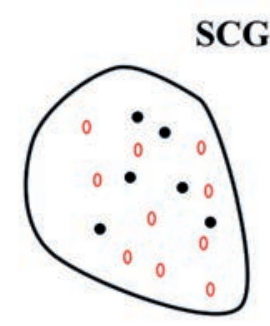

• : CGRP

$0:$ VEGF-A
E17.5
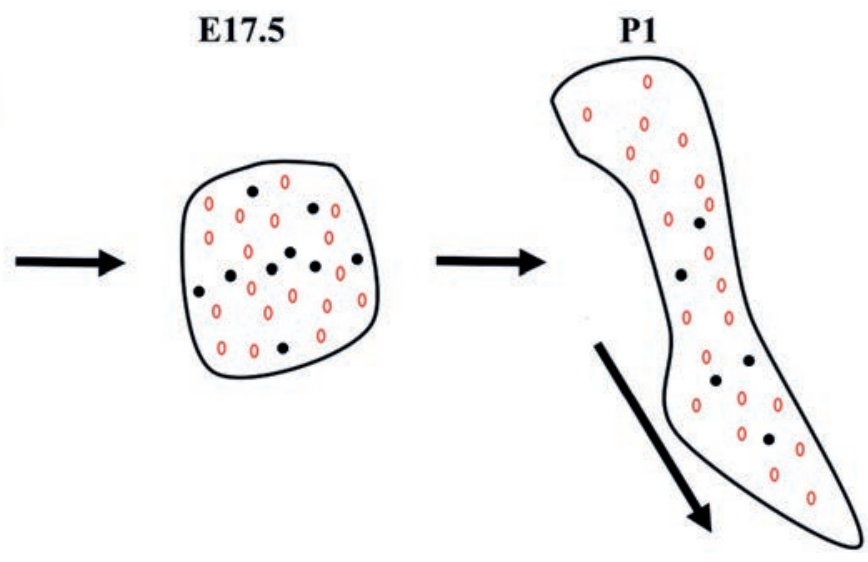

Figure 4. Schematic image of the changed localization of CGRP and VEGF-A from 14.5 to P1. Oval form represents VEGF-A reactions; small spots represents CGRP. Oral movement may affect CGRP expression in various terminal regions of the head and neck during the development process. 


\section{References}

1. Walker CS, Li X, Whiting L, Glyn-Jones S, Zhang S, Hickey AJ, et al. Mice lacking the neuropeptide alpha-calcitonin gene-related peptide are protected against diet-induced obesity. Endocrinology 2010;151:4257-69.

2. Yu XJ, Li CY, Wang KY, Dai HY. Calcitonin gene-related peptide regulates the expression of vascular endothelial growth factor in human $\mathrm{HaCaT}$ keratinocytes by activation of ERK1/2 MAPK. Regul Pept 2006;137: 134-9.

3. Kestell GR, Anderson RL, Clarke JN, Haberberger RV, Gibbins IL. Primary afferent neurons containing calcitonin gene-related peptide but not substance $\mathrm{P}$ in forepaw skin, dorsal root ganglia, and spinal cord of mice. J Comp Neurol 2015;523:2555-69.

4. Bidegain M, Roos BA, Hill EL, Howard GA, Balkan W. Calcitonin gene-related peptide (CGRP) in the developing mouse limb. Endocr Res 1995;21:74355.

5. Lindh B, Risling M, Remahl S, Terenius L, Hökfelt T. Peptide-immunoreactive neurons and nerve fibres in lumbosacral sympathetic ganglia: selective elimination of a pathway-specific expression of immunoreactivities following sciatic nerve resection in kittens. Neuroscience 1993;55:545-62.

6. Schmitt M, Kummer W, Heym C. Calcitonin gene-related peptide (CGRP)immunoreactive neurons in the human cervico-thoracic paravertebral ganglia. J Chem Neuroanat 1988;1:287-92.

7. Gurusinghe CJ, Bell C. Substance P immunoreactivity in the superior cervical ganglia of normotensive and genetically hypertensive rats. J Auton Nerv Syst 1989;27:249-56.

8. Kay AB. Calcitonin gene-related peptide- and vascular endothelial growth factor-positive inflammatory cells in late-phase allergic skin reactions in atopic subjects. J Allergy Clin Immunol 2011;127:232-7.

9. Tuo Y, Guo X, Zhang X, Wang Z, Zhou J, Xia L, et al. The biological effects and mechanisms of calcitonin gene-related peptide on human endothelial cell. J Recept Signal Transduct Res 2013;33:114-23.

10. Samii A, Unger J, Lange W. Vascular endothelial growth factor expression in peripheral nerves and dorsal root ganglia in diabetic neuropathy in rats. Neurosci Lett 1999;262:159-62.

11. Masliukov PM, Emanuilov AI, Madalieva LV, Moiseev KY, Bulibin AV, Korzina MB, et al. Development of nNOS-positive neurons in the rat sensory and sympathetic ganglia. Neuroscience 2014;256:271-81.

12. Sondell M, Sundler F, Kanje M. Vascular endothelial growth factor is a neurotrophic factor which stimulates axonal outgrowth through the flk-1 receptor. Eur J Neurosci 2000;12:4243-54.

13. Sondell M, Kanje M. Postnatal expression of VEGF and its receptor flk-1 in peripheral ganglia. Neuroreport 2001; 12:105-8.

14. Krajewska M, Smith LH, Rong J, Huang X, Hyer ML, Zeps N, et al. Image analysis algorithms for immunohistochemical assessment of cell death events and fibrosis in tissue sections. J Histochem Cytochem 2009;57:649-63.

15. K Mitsuoka, T Kikutani, I Sato. Morphological relationship between the superior cervical ganglion and cervical nerves in Japanese cadaver donors. Brain Behav 2016;7:1-9.

16. Vukojevic K, Filipovic N, Tica Sedlar I, Restovic I, Bocina I, Pintaric I, et al. Neuronal differentiation in the developing human spinal ganglia. Anat Rec (Hoboken) 2016;299:1060-72.

17. Soltanpour N, Santer RM. Preservation of the cervical vagus nerve in aged rats: morphometric and enzyme histochemical evidence. J Auton Nerv Syst 1996; 60:93-101.

18. Schotzinger RJ, Landis SC. Postnatal development of autonomic and sensory innervation of thoracic hairy skin in the rat. A histochemical, immunocytochemical, and radioenzymatic study. Cell Tissue Res 1990;260:575-87.

19. Starchenko II, Vitko YN, Prylutskyi OK, Bilokon SO, Vynnyk NI. Morphological and immunohistochemical characteristics of human trigeminal ganglion neurons in the prenatal period of development. Wiad Lek 2017;70:561-5.

20. Cui Y, Giesy SL, Hassan M, Davis K, Zhao S, Boisclair YR. Hepatic FGF21 production is increased in late pregnancy in the mouse. Am J Physiol Regul Integr Comp Physiol 2014;307:290-8.

21. Piehl F, Ji RR, Cullheim S, Hökfelt T, Lindholm D, Hughes RA. Fibroblast growth factors regulate calcitonin generelated peptide mRNA expression in rat motoneurons after lesion and in culture. Eur J Neurosci 1995;7:1739-50.

22. Azuma Y, Miwa Y, Sato I. Expression of CGRP in embryonic mouse masseter muscle. Ann Anat 2016;206:34-47.

23. Maeda Y, Miwa Y, Sato I. Expression of CGRP, vasculogenesis and osteogenesis associated mRNAs in the developing mouse mandible and tibia. Eur J Histochem 2017;61:2750.

24. Masliukov PM, Emanuilov AI, Moiseev K, Nozdrachev AD, Dobrotvorskaya S,
Timmermans JP. Development of noncatecholaminergic sympathetic neurons in para-and prevertebral ganglia of cats. Int J Dev Neurosci 2015;40:76-84.

25. Robinson A. Cunningham's text-book of anatomy. New York: W. Wood and Co.; 1922.

26. Standring S. Gray's anatomy. 39th ed. New York: Churchill Livingstone; 2005.

27. Schneider ML, Roughton EC, Koehler AJ, Lubach GR. Growth and development following prenatal stress exposure in primates: an examination of ontogenetic vulnerability. Child Dev 1999; 70:263-74.

28. Schneider RJ, Khantzian EJ. Psychotherapy and patient needs in the treatment of alcohol and cocaine abuse. Recent Dev Alcohol 1992;10:165-78.

29. Schou WS, Ashina S, Amin FM, Goadsby PJ, Ashina M. Calcitonin generelated peptide and pain: a systematic review. J Headache Pain 2017; 18:34.

30. Cornish J, Callon KE, Lin CQ, Xiao CL, Gamble GD, Cooper GJ, et al. Comparison of the effects of calcitonin gene-related peptide and amylin on osteoblasts. J Bone Miner Res 1999;14: 1302-9.

31. Fontaine B, Klarsfeld A, Hökfelt T, Changeux JP. Calcitonin gene-related peptide, a peptide present in spinal cord motoneurons, increases the number of acetylcholine receptors in primary cultures of chick embryo myotubes. Neurosci Lett 1986;71:59-65.

32. Miles K, Greengard P, Huganir RL. Calcitonin gene-related peptide regulates phosphorylation of the nicotinic acetylcholine receptor in rat myotubes. Neuron 1989;2:1517-24.

33. Mulle C, Benoit P, Pinset C, Roa M, Changeux JP. Calcitonin gene-related peptide enhances the rate of desensitization of the nicotinic acetylcholine receptor in cultured mouse muscle cells. Proc Natl Acad Sci USA 1988;85:5728-32.

34. New HV, Mudge AW. Calcitonin generelated peptide regulates muscle acetylcholine receptor synthesis. Nature 1986; 323:809-11.

35. Sisask G, Silfverswärd CJ, Bjurholm A, Nilsson O. Ontogeny of sensory and autonomic nerves in the developing mouse skeleton. Auton Neurosci 2013; 177:237-43.

36. Villa I, Dal Fiume C, Maestroni A, Rubinacci A, Ravasi F, Guidobono F. Human osteoblast-like cell proliferation induced by calcitonin-related peptides involves PKC activity. Am J Physiol Endocrinol Metab 2003;284:627-33. 